This is a self-archived - parallel published version of this article in the publication archive of the University of Vaasa. It might differ from the original.

\title{
Multi-objective optimisation method for coordinating battery storage systems, photovoltaic inverters and tap changers
}

Author(s): Hashemipour, N.; Aghaei, Jamshid; Lotfi, Mohamed; Niknam, Taher; Askarpour, Mohammad; Shafie-khah, Miadreza; Catalão, Joao P.S.

Title: $\quad$ Multi-objective optimisation method for coordinating battery storage systems, photovoltaic inverters and tap changers

Year: $\quad 2020$

Version: Final draft (post print, aam. accepted manuscript)

Copyright C2020 IET. This paper is a postprint of a paper submitted to and accepted for publication in IET renewable power generation and is subject to Institution of Engineering and Technology Copyright. The copy of record is available at the IET Digital Library.

Please cite the original version:

Hashemipour, N., Aghaei, J., Lotfi, M., Niknam, T., Askarpour, M., Shafie-khah, M., \& Catalão, J.P.S., (2020). Multi-objective optimisation method for coordinating battery storage systems, photovoltaic inverters and tap changers. IET renewable power generation 14(3), 475-483.

https://doi.org/10.1049/iet-rpg.2019.0644 


\title{
Multi-Objective Optimization Method for Coordinating Battery Storage Systems, Photovoltaic Inverters and Tap Changers
}

\author{
N. Hashemipour ${ }^{1}$, J. Aghaei ${ }^{1}$, M. Lotfi ${ }^{2}$, T. Niknam ${ }^{1}$, M. Askarpour ${ }^{1}$, M. Shafie-khah ${ }^{3}$, J.P.S. Catalão ${ }^{2, *}$ \\ ${ }^{1}$ Department of Electrical and Electronics Engineering, Shiraz University of Technology, Shiraz, Iran (e-mails: \\ naser_hashemipour@yahoo.com; aghaei@sutech.ac.ir; niknam@sutech.ac.ir; mohammad.askarpour@gmail.com). \\ ${ }^{2}$ Faculty of Engineering of the University of Porto and INESC TEC, Porto 4200-465, Portugal (e-mails: mohd.f.lotfi@gmail.com; \\ catalao@fe.up.pt). \\ ${ }^{3}$ School of Technology and Innovations, University of Vaasa, 65200 Vaasa, Finland (e-mail: miadreza@gmail.com). \\ * Corresponding author: catalao@fe.up.pt
}

\begin{abstract}
The many well-established advantages of distributed generation (DG) make their usage in active distribution networks prevalent. However, uncontrolled operation of DG units can negatively interfere with the performance of other equipment, such as tap-changers, in addition to resulting in sub-optimal usage of their potential. Thus, adequate scheduling/control of DG units is critical for operators of the distribution system to avoid those adverse effects. A linearized model of a multi-objective method for coordinating the operation of photovoltaics (PVs), battery storage systems, and tap-changers is proposed. Three objective functions are defined for simultaneously enhancing voltage profile, minimizing power losses, and reducing peak load power. The formulated multi-objective problem is solved by means of the epsilon-constraint technique. A novel decision-making methodology is offered to find the Pareto optimality and select the preferred solution. To assess to proposed model's performance, it is tested using 33-bus IEEE test system. Consequently, tap-changers suffer lessened stress, the batteries Stateof-Charge (SoC) is kept within adequate limits, and the DG units operation is at higher efficiency. The obtained results verify the effectiveness of this approach.
\end{abstract}

Keywords: Multi-Objective Optimization, Battery Storage Systems, Photovoltaic Inverters, Tap Changers, Distribution Networks.

\section{Nomenclature}

A. Indices

i Buses

$t \quad$ Time (hours)

Slack Subscript for Slack Bus

$P V \quad$ Buses with PV generation unit

${ }^{t_{\text {Peak }}} \quad$ Peak load (hours)

${ }^{t_{\text {Heavy }}} \quad$ Heavy load (hours)

$t_{\text {Light } \quad \text { Light load (hours) }}$

\section{B. Constants}

$S_{\text {bat }} \quad$ Battery capacity in unit of power

$P_{\max } \quad$ Inverter's maximum allowed active power under

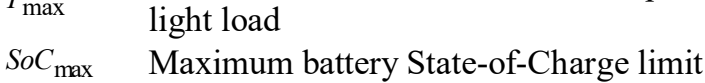

$S o C_{\min } \quad$ Minimum battery State-of-Charge limit

$V_{\max } \quad$ Maximum bus voltage limit

$V_{\min } \quad$ Minimum bus voltage limit

$S_{\text {inv }} \quad$ Inverter capacity

$Q_{\max } \quad$ Inverter maximum allowed reactive power under

heavy load

$\eta_{\text {inv }} \quad$ Inverter efficiency

$\eta_{C} \quad$ Battery energy efficiency

\section{Variables}

$A_{\text {hbat_in }} \quad$ Battery input current (Ampere-hour)

$A h_{\text {delivered }}$ Battery output current (Ampere-Hour)

$A h_{\text {capacity }}$ Battery capacity

$\operatorname{SoC}(t) \quad$ Battery State-of-Charge at time $t$

$V_{i}(t) \quad$ Voltage at Bus $i$ at time $t$

$P_{g_{i}}(t) \quad$ Generation of active power at Bus $i$ at time $t$

$P_{l_{i}}(t) \quad$ Active load at Bus $i$ at time $t$
$P_{d_{i_{\text {nom }}}} \quad$ Active load at Bus $i$ in voltage 1 p.u.

$Q_{g_{i}}(t)$ Generation of reactive power at Bus $i$ at time $t$

$Q_{l_{i}}(t) \quad$ Reactive load Bus $i$ at time $t$

$P_{\text {loss }}(t)$ Grid losses at time $t$

$Y_{i}(t) \quad$ Linearization of the voltage deviation function (auxiliary variable)

$P_{M P P T}(t)$ Maximum PV active power achievable using the

$P_{M P P T}(t) \quad$ MPPT algorithm

$P_{s i} \quad$ Solar irradiance in kilowatt per square meter

$\left(\mathrm{kW} / \mathrm{m}^{2}\right)$

$f \quad$ Voltage deviation function

$u \quad$ BESS binary variable (0-charging; 1-discharging)

\section{Abbreviations}

BESS Battery Energy Storage System

DER Distributed Energy Resources

DG Distributed Generation

MPPT Maximum Power Point Tracking

PV Photovoltaic

SoC State-of-Charge

\section{Introduction}

\section{A. Motivation and Aim}

Renewable power generation has become of paramount importance on the account of well-established advantages. Accordingly, international policies have been increasingly steered towards the proliferation of renewable energy. As an example of this, back in 2005 the number of countries which held auctions to promote the use of distributed generation (DG) was a mere six. By 2016, this figure had reached at least 67 (more than a tenfold increase in ten years). Photovoltaic (PV) panels in particular have become a significantly more popular form of DG due to technological progress and declining prices. This is reflected in the global total installed PV capacity, which went up from 40 to 219 GW between 2010 and 2015 (fivefold in five years) and are anticipated to account for around 
7 percent of total global energy generation by 2030 [1]. Aside from DG, energy storage has become another critical element of distributed energy resources, and its importance is yet to increase. Furthermore, the amount of total stationary energy storage capacity by 2025 is forecast to be tenfold that of 2017 [2].

While there are many merits to this ongoing increased penetration of DG and storage units in power systems, their combined presence can interfere with grid controllers. Therefore, coordination between those distributed energy resources (DER) and grid controllers is crucial to ensure proper operation of the system. Accordingly, a strategy for coordinated operation of PV units, energy storage, and grid controllers based on multi-objective optimization is proposed and tested in this paper.

\section{B. Literature Review}

Determining optimal hourly voltage reference values for network controllers is one of the established approaches for voltage control [3]-[5]. These values are time-variant and are used as controller inputs to achieve required objectives.

Another proposed approach [6] for voltage control is based on fuzzy logic. The deviation of load and voltage levels is measured from a reference value and sent to the fuzzy logic controller, according to which appropriate control decisions can be taken. Control signals can be generated based on instantaneous measurement of voltage or active/reactive power values at installed locations of distributed generation. [7].

A cooperative protocol [8] has been previously proposed, providing voltage control at multiple feeders each having unbalanced load diversity and a transformer tap-changer in the presence of DG units. In this protocol, there is a conflict between two of the objectives which are defined for each of the control agents. The first objective aims to achieve the system requirements of minimizing voltage deviation and reducing tap operation. Accordingly, each agent makes a decision based on local information such that operational interference is mitigated. In [9], the control of reactive power injection considering battery energy storage was presented, demonstrating voltage profile enhancement.

Multiple studies [10]-[12] have performed sensitivity analyses to identify the best control actions. State estimation can be used in online applications to calculate the control parameters [13], [14]. In [15], a comparison between various battery charging and discharging strategies was presented. In [16], distributed control using a consensus algorithm was used for voltage regulation, while localized control was used to maintain the battery energy storage systems (BESSs) State-of-Charge (SoC) within the desired range. A dynamic programming algorithm was proposed in [17] to minimize output fluctuations in BESSs.

In [18], various voltage regulators' control strategies were studied, in addition to the potential impact of smart transformers (made up of a fixed tap transformer and a power electronic voltage regulator) to mitigate voltage violations in the system. By automatically varying the line voltage in response to changes in load, smart transformers were shown to have potential to reduce voltage variations.

The need for additional equipment can be prevented by segmenting the network, based on the (transformer) distance between voltage controllers, into various control areas [19]. In [20], suitable controllers are designed based on small signal modelling. In [21], a voltage control loop within PV inverters was implemented in order to maintain the voltage within acceptable bounds by absorbing or injecting reactive power. In [22], dispatching computes the desired values of active and reactive power, in order to be forward them to local channel controllers by means of telecommunication links. In [23], voltage emergency situations were studied in order to devise a strategy for reactive power injection (or absorption) in such cases.

In [24], voltage control equipment are used to impose the permissive limits. Afterwards, a combination of local and remote control reduces the system losses. In [25], a twostage approach was presented for solving the optimal voltage regulation problem in unbalanced radial distribution systems with PV generation.

Relevant studies were summarized and compared in Table 1. While many studies consider voltage profile improvement and losses reduction, they do not focus on peak reduction. In addition, almost none present a linearized formulation, which can greatly enhance the computational efficiency of the optimization and decision-making models.

Table 1 Summary and comparison of relevant studies in scientific literature.

\begin{tabular}{|c|c|c|c|c|c|c|}
\hline \multirow{2}{*}{ Ref } & \multirow{2}{*}{ Year } & \multicolumn{3}{|c|}{$\begin{array}{c}\text { Objective(s): } \\
\text { Improvement of }\end{array}$} & $\begin{array}{c}\text { Battery } \\
\text { Modelling }\end{array}$ & $\begin{array}{c}\text { Linear } \\
\text { Formula }\end{array}$ \\
\cline { 3 - 5 } & & $\begin{array}{c}\text { Peak } \\
\text { Reduction }\end{array}$ & Losses & $\begin{array}{c}\text { Voltage } \\
\text { Profile }\end{array}$ & & No \\
\hline 4 & 2010 & No & No & Yes & No & No \\
\hline 5 & 2012 & No & Yes & Yes & No & No \\
\hline 6 & 2013 & No & No & Yes & No & No \\
\hline 13 & 2014 & No & No & Yes & No & No \\
\hline 14 & 2016 & No & No & Yes & No & No \\
\hline 17 & 2016 & No & No & Yes & No & No \\
\hline $\begin{array}{c}\text { Proposed Method } \\
\text { (Current Study) }\end{array}$ & Yes & Yes & Yes & Yes & Yes \\
\hline
\end{tabular}

\section{Scope and Contributions}

In this paper, a linearized model for coordinating voltage controllers in active distribution networks with PV generation is proposed, having three simultaneous objectives: voltage profile improvement, reduction of power losses, and minimizing peak load power. These objectives can be achieved through voltage control due to the dependence of electrical load power on voltage, in addition to power shifting through energy storage utilization. Accordingly, suitable planning of peak consumption hours and setting a suitable voltage level will result in reduction of peak load power. Moreover, the network state during peak hours is improved by shifting the injection of PV-generated power from peak production to peak consumption hours through the use of energy storage systems. Optimal utilization of energy storage is carried out by taking into consideration the constraints of maintaining their SoC within suitable values and maximizing their lifespan. The linearized problem formulation increases efficiency and computational performance of the coordinated control model.

\section{Proposed Voltage Control Characterization}

The single-line diagram in Fig. 1 shows a DG unit comprised of PV panel(s) and a BESS connected to a distribution grid. It can be seen that the time-varying nature of the PV generation (and thereby the magnitude and direction of power which is exchanged between the DG unit and the grid) results in a voltage drop across the line impedance, as approximated by (1) [3]:

$$
\Delta V \approx \frac{R P_{i}+X Q_{i}}{V_{i}^{*}}
$$


which can be simplified by considering $V_{i}$ as the reference voltage:

$$
\Delta V \approx R P_{i}+X Q_{i}
$$

where, $P_{i}= \pm P_{g_{i}}-P_{l_{i}}$ and $Q_{i}= \pm Q_{g_{i}}-Q_{l_{i}}$.

According to the above formula, voltage regulation is

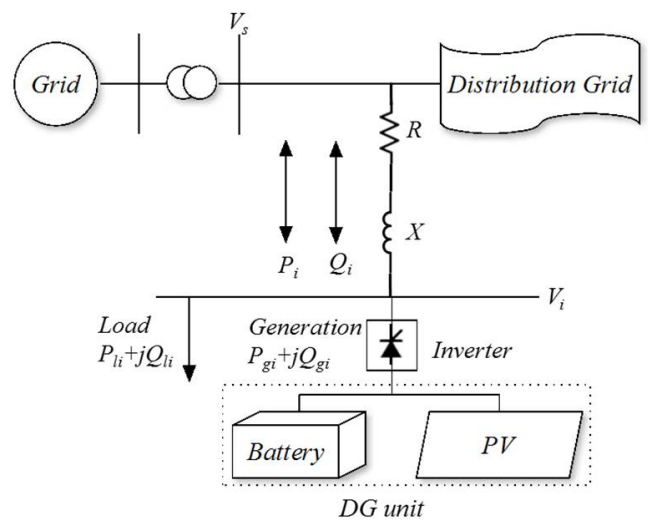

Fig. 1. Single-line diagram of $D G$ unit connection to a Distribution Grid.

dependent upon DG active and reactive power. However, the priority is maximizing utilization of the generated power, keeping in mind that the main purpose behind installing DG units is acquiring active power.

Optimal utilization of the PV panel(s), can be achieved using methods like maximum power point tracking (MPPT). Nevertheless, this is associated with some issues. During hours of peak (solar) irradiance, the system experiences a voltage spike. However, this is may not be met by sufficient peak generation from the PVs, in which case the network can experience a severe voltage collapse due to high loading conditions. Meanwhile, the bus voltages must be constrained within their maximum and minimum limits, as expressed by equations (3) and (4), respectively.

$$
\begin{aligned}
& V_{i}(t) \leq V_{\text {max }} \\
& V_{i}(t) \geq V_{\text {min }}
\end{aligned}
$$

The connection of BESSs alongside the DG can be used to address these issues by utilizing energy storage. Namely, the active power generated during the day by PV panel(s) is injected to the grid as required at any given time. Any excess power is stored by charging the BESS, which can later be discharged and injected into the network when needed. In this way, not only is overvoltage due to DG peak production avoided, but also severe voltage drops in during peak load hours mitigated.

However, BESSs should be connected in such a way that they do not interfere neither with the active/reactive power of voltage controllers nor with the tap changer. In addition, their charging/discharging needs to be scheduled. With this in mind, Equations (5)-(12) provide the governing equations for the connected BESS and its SoC.

$$
\begin{gathered}
A h_{\text {bat_in }}=\frac{P_{M P P T}-\left(\frac{P_{g}}{\eta_{\text {inv }}}\right)}{V} \times 1 h \\
A h_{\text {Delivered }}=A h_{\text {bat_in }} \times \eta_{C} \\
S o C(t)=S o C(t-1)-u \cdot \frac{A h_{\text {Delivered }}}{A h_{\text {Capacity }}}+(1-u) \cdot \frac{A h_{\text {bat_in }}}{A h_{\text {Capacity }}} \\
A h_{\text {Delivered }} \leq u \cdot A h_{\text {bat_in }}
\end{gathered}
$$

$$
\begin{gathered}
u=\{0,1\} \\
P_{g}(t) \leq P_{M P P T}(t)+\operatorname{SoC}(t) \cdot S_{b a t} \\
\left(P_{g_{i}}(t)-P_{M P P T}(t)\right) \cdot \eta_{c} \leq r \cdot S_{b a t} \\
P_{M P P T}(t)-P_{g_{i}}(t) \leq r \cdot S_{b a t}
\end{gathered}
$$

In Equation (5), the input current (in terms of amperehour) to the battery is calculated. $P_{M P P T}$ and $P_{g}$ correspond to maximum achievable active power generation through MPPT and current active power generation, respectively. $V$ is the voltage across the battery terminals. $\eta_{\text {inv }}$ is the inverter efficiency. In Equation (6), the output current (amperehour) of the battery is equal to the input current multiplied by the battery efficiency, $\eta_{c}(<1)$. In Equation (7), the SoC at hour $(t)$ is calculated as that of the previous hour $(t-l)$, minus any discharged current, plus any input current (in ampere-hour). In Equation (8), the discharged current is less than or equal the input current, in which the charging/discharging binary variable is u.. As defined in Equation (9), $u$ can be equal to 0 (charging), or 1 (discharging), meaning that the BESS can only be in one of the two states for a given hour. In Equation (10), the DG unit's output power is constrained by the sum of the maximum achievable power generation through MPPT and the BESS SoC. The input/output current is limited to a fraction (determined by $r$ ) of battery capacity to prevent damage in Equations (11) and (12). Equations (5)-(12) thus determine and constrain the amount of injected power by the DG unit to the grid. Given that inappropriate values of the SoC can cause damage to the battery, the following constraints limit it within the permitted values to prevent this from happening.

$$
\begin{aligned}
& \operatorname{SoC}(t) \leq S o C_{\text {max }} \\
& \operatorname{SoC}(t) \geq S o C_{\text {min }}
\end{aligned}
$$

The DG unit, made up of the coupled BESS and PV panel(s), is connected to the grid by means of an inverter. The inverter converts current (and thereby power) from DC to $\mathrm{AC}$ at the network frequency. The inverter also controls active and reactive power, being limited by the capability curve of inverters, a limitation that should be applied to the problem. This capability curve is given in Equation (15) and further visualized in Fig. 2.

$$
S_{i n v}=\sqrt{P_{g}^{2}+Q_{g}^{2}}
$$

Equation (15) can be linearized around a certain operating apparent power $(|S|)$. There are two principal operating points: active and reactive operation modes, which are demonstrated in Fig. 3 (a) and (b) respectively.

The more adequate mode must be selected based on the current the situation of the grid. In other words, choice of

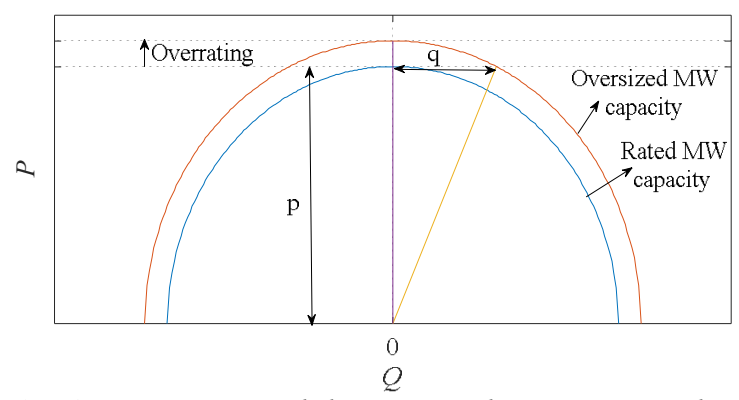

Fig. 2. Inverter capability curve showing a graphical representation of the active $(P)$ and reactive $(Q)$ power operating range. 
the proper point depends on $P_{M P P T}$ as well as the loading of the grid $\left(P_{0}\right)$.

A fuzzy decision maker is employed to enhance the accuracy of the decision on inverter mode and clarify the definition of each operation mode. Prior to the definition of the proposed fuzzy decision maker, active and reactive modes are explained.

\section{1) Active mode:}

During the operation, when transaction of the active power between grid and generating unit is more effective, the inverter power factor is confined to a near-unity lead-lag period to maximize active power injection to the grid (while considering grid standards and local regulations) as demonstrated in Fig. 3 (a).
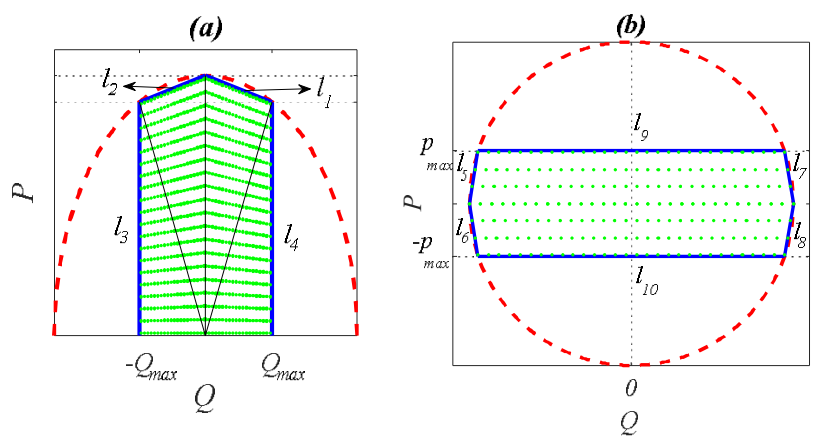

Fig. 3. Inverter capability curve indicating the linearization points in the case of: (a) Active mode, (b) Reactive mode.

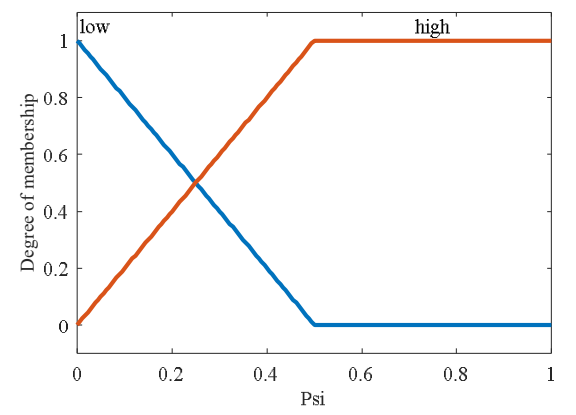

Fig. 4. Fuzzy membership functions of the first input.

This is governed by the inequalities in Equation (16)(19), which are further elaborated in detail in an appendix of this manuscript.

$$
\begin{aligned}
& l_{1}\left(P V, t_{\text {active }}\right) \leq 0 \\
& l_{2}\left(P V, t_{\text {active }}\right) \leq 0 \\
& l_{3}\left(P V, t_{\text {active }}\right) \geq 0 \\
& l_{4}\left(P V, t_{\text {active }}\right) \leq 0
\end{aligned}
$$

\section{2) Reactive mode:}

During some situations like huge DG power generation and light load demand, overvoltage can be problematic. Meanwhile, the inverter's reactive power operation mode actually enhances the grid's state. As such, a low power factor is preferred in those hours to maximize reactive power injection as demonstrated in Fig. 3 (b). This is modelled by the constraints listed in Equation (20)-(25), which are also elaborated further in the appendix:

$$
\begin{aligned}
& l_{5}\left(P V, t_{\text {reactive }}\right) \leq 0 \\
& l_{6}\left(P V, t_{\text {reactive }}\right) \geq 0
\end{aligned}
$$

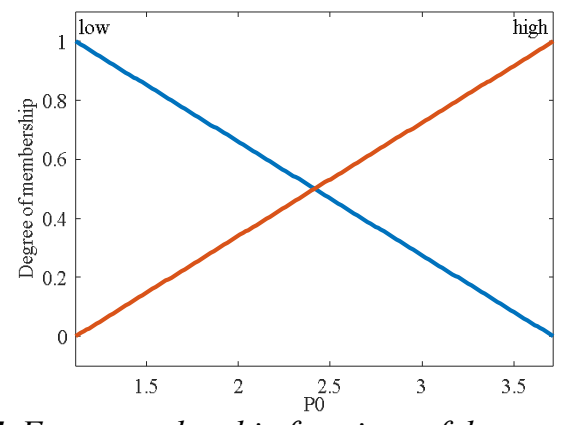

Fig. 5. Fuzzy membership functions of the second input.

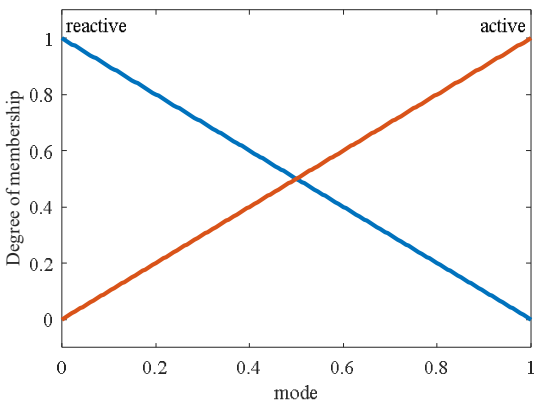

Fig. 6. Fuzzy membership functions of the output.

$$
\begin{aligned}
& l_{7}\left(P V, t_{\text {reactive }}\right) \leq 0 \\
& l_{8}\left(P V, t_{\text {reactive }}\right) \geq 0 \\
& l_{9}\left(P V, t_{\text {reactive }}\right) \leq 0 \\
& l_{10}\left(P V, t_{\text {reactive }}\right) \geq 0
\end{aligned}
$$

As it was stated, the inverter mode selection is performed by a fuzzy decision maker. The fuzzy rules are defined regarding the eco-friendly policies as well as down-scaling trend of the non-renewable resources. To this end, $P_{s i}$ and $P_{0}$, which can be remotely determined by the distribution system operator, are considered as the inputs of the fuzzy system.

Two membership functions named high and low are defined to represent the $P_{s i}$ behavior as can be seen in Fig. (4). Similarly, $P_{0}$ is modeled by two membership functions high and low as is illustrated in Fig. (5). Finally, two membership functions named active and reactive are defined correspond to each mode of operation as can be seen in Fig. 6.

It must be noted that the definition of these membership functions is at the operator's preferences and/or priorities and in the presented method they have been specified based on maximizing the active power injection to the grid. Table 2 provides the rules of the fuzzy decision maker and a summarized reason for each rule.

Table 2 The rules and reasons thereof for the fuzzy decision maker.

\begin{tabular}{|c|c|c|c|}
\hline$P_{s i}$ & $P_{0}$ & $\begin{array}{c}\text { Inverter } \\
\text { mode }\end{array}$ & Reason \\
\hline high & high & active & $\begin{array}{c}\text { The first priority and policy is the } \\
\text { maximum usage of renewable resources. }\end{array}$ \\
\hline high & low & reactive & $\begin{array}{c}\text { Battery is charged by PV. While inverter } \\
\text { provides the reactive power support to the } \\
\text { orid }\end{array}$ \\
\hline low & high & active & $\begin{array}{c}\text { The battery is de-charged in absence of } \\
\text { renewable generation and heavy load } \\
\text { condition }\end{array}$ \\
\hline low & low & reactive & $\begin{array}{c}\text { Battery is charged from the grid in low } \\
\text { load condition. }\end{array}$ \\
\hline
\end{tabular}


At this point, the linear inverter model has been established and the next step is to linearize the load flow equations. The tap-changer (which is one of the decision variables) is modelled using the $\pi$ model [26].

The load flow is modelled using linear formulation as shown in Equation (26)-(29) [27]:

$$
\begin{gathered}
{\left[\begin{array}{r}
-A_{r} \\
-A_{i}
\end{array}\right]=\left[\begin{array}{cc}
B_{r}+C_{r} & B_{i}-C_{i} \\
B_{i}+C_{i} & -B_{r}+C_{r}
\end{array}\right] \cdot\left[\begin{array}{c}
V_{r} \\
V_{i}
\end{array}\right]} \\
A=Y_{N S} \cdot V_{s}-2 h \cdot S_{P N}^{*}+h \cdot S_{I N}^{*} \\
B=h^{2} \cdot \operatorname{diag}\left(S_{P N}^{*}\right) \\
C=Y_{N N}-h^{2} \cdot \operatorname{diag}\left(S_{Z N}^{*}\right)
\end{gathered}
$$

where:

$$
\begin{gathered}
Y_{\text {bus }}=\left[\begin{array}{ll}
Y_{S S} & Y_{S N} \\
Y_{N S} & Y_{N N}
\end{array}\right] \\
h=\frac{1}{V_{\text {nom }}} \underset{\substack{\text { in p.u.system } \\
V_{\text {nom }}=1 \text { p.u. }}}{\Rightarrow} h=1
\end{gathered}
$$

Constant power, current, and impedance loads are represented by vectors $S_{\mathrm{PN}}, \mathrm{S}_{\mathrm{IN}}$, and $\mathrm{S}_{\mathrm{ZN}}$, respectively. The reference used for this formulation [27] describes in detail the construction of matrices $A, B$, and $C$. The proposed multi-objective model aims at improving the voltage profile, in addition to reducing losses and peak load power. Accordingly, the three objective functions need to be simultaneously minimized.

The first objective function is related to the voltage profile. This function, to be minimized, is expressed as follows:

$$
f=\left|V_{i}(t)-1\right|
$$

In order to linearize the objective function for voltage profile, an auxiliary positive variable is used to transform Equation (32) into the form shown in Equation (33), which is the form used in the model:

$$
\begin{aligned}
& \min y_{i}(t) \\
& y_{i}(t) \geq V_{i}(t)-1, y_{i}(t) \geq 1-V_{i}(t), y_{i}(t) \geq 0
\end{aligned}
$$

In Equation (34), the system's power losses are derived by summing the losses of each line (ij), having an impedance of $Z_{i j}$ and current $I_{i j}(t)$ passing through it at time $t$ : Minimizing this value corresponds to the second objective function in this problem.

$$
P_{\text {loss }}(t)=I_{i j}^{2}(t) \cdot Z_{i j}
$$

To linearize this function, the system losses can alternatively be represented as the difference between the system's total production and consumption as shown in Equation (35).

$$
P_{\text {loss }}(t)=\sum_{i} P_{g_{i}}(t)-\sum_{i} P_{l_{i}}(t)
$$

Finally, the third objective function is related to minimizing peak load power. There are various loads in active distribution networks, which, according to voltage dependency, are placed in one of three categories: constant power, constant current or constant impedance. Due to sensitivity of the load to the voltage, peak power can be controlled to some extent by changing the voltage. To enhance the computational performance of the algorithm and also to deal with the lack of information on the type of every single load in the system, a well-established rule-ofthumb is employed. This assumes direct proportionality between load and power, indicating that with every $\pm 1 \%$ change in voltage there is a $\pm 1 \%$ in power [28].

As the problem is implemented in per unit (p.u.) system, the linear relation of the consumption power and voltage can be derived as is seen in (36) and (37).

$$
\begin{gathered}
P_{\text {Peak }}-P_{0} \approx \frac{P_{0}-0.99 P_{0}}{1-0.99} \times\left(V_{\text {Slack }}-1\right) \\
P_{\text {Peak }} \approx P_{0} \times V_{\text {Slack }}
\end{gathered}
$$

where

$$
P_{0}=\sum P_{d_{\text {inom }}}
$$

$P_{P e a k}$ and $V_{\text {Slack }}$ are the slack bus peak power and voltage, respectively. Given that Equation (37) is required only during peak hours, the objective function associated with peak power reduction is in the form of Equation (39), in which the voltage level is decreased during peak hours by the tap-changer.

$$
P\left(t_{\text {Peak }}\right) \approx P_{0} \times V\left(\text { Slack, } t_{\text {Peak }}\right)
$$

The considered decision variables are: the inverter's reactive power output, the position of the tap-changer, $P_{i}$ and $Q_{i}$ (associated with the PV power output), and the SoC of the battery energy storage system.

By solving this multi-objective optimization problem using the introduced objective functions and constraints, an appropriate time schedule can be obtained for coordinated operation of the grid's elements.

\section{Multi-Objective Optimization and Decision Making Model}

The Pareto front is a set of solutions satisfying a multiobjective optimization problem as opposed to the single global optimum value. Since the improvement of one objective function can result in the worsening of the others (i.e., a trade-off has to be made between the different objective functions), decision-making is necessary to choose a most "preferred" optimal solution. Thus, specific methods have to be used for 1) solving the optimization problem and 2) decision-making regarding the optimal solution. The epsilon-constraint method one such method suitable for dealing with multi-objective optimization problems [29].

This proposed method is elaborated in the flowchart presented in Fig. 7. In the epsilon-constraint method, one of the objective functions is set as the main one while the other objective functions are modelled as constraints. In this paper, the objective functions introduced in Equation (33), (35), and (39) were modelled as $f_{1}=\sum_{t} \sum_{i} y_{i}(t), f_{2}=$ $\sum_{t} P_{\text {loss }}(t)$ and $f_{3}=\sum_{t_{\text {peak }}} P\left(t_{\text {peak }}\right) \cdot f_{1}$ (voltage profile) was considered the main objective, while $f_{2}$ (power losses) and $f_{3}$ (peak load power) were added as problem constraints. It should be noted the objective functions have to be linearly independent of each other, which will be confirmed in the next section.

As such, the multi-objective optimization problem is presented below:

$$
\min f_{1}(\bar{X}) \text { subject to } f_{2}(\bar{X}) \leq e_{2}, f_{3}(\bar{X}) \leq e_{3}
$$




$$
\begin{aligned}
& e_{2}=f_{2_{\text {min }}}+\left(\frac{f_{2_{\text {max }}}-f_{2_{\text {min }}}}{q_{2}}\right) \cdot n_{2}, n_{2}=1,2, \ldots, q \\
& e_{3}=f_{3_{\text {min }}}+\left(\frac{f_{3_{\text {max }}}-f_{3_{\text {min }}}}{q_{3}}\right) . n_{3}, n_{3}=1,2, \ldots, q
\end{aligned}
$$

$q$ is the required number of iterations to generate the Pareto set. $\bar{X}$ refers to the decision variables, while $f_{i_{\text {min }}}$ and $f_{i_{\text {max }}}$ are taken from the payoff table which is shown in Equation (43).

$$
\Phi=\left[\begin{array}{lll}
f_{1}^{*}\left(\bar{X}_{1}^{*}\right) & f_{2}\left(\bar{X}_{1}^{*}\right) & f_{3}\left(\bar{X}_{1}^{*}\right) \\
f_{1}\left(\bar{X}_{2}^{*}\right) & f_{2}^{*}\left(\bar{X}_{2}^{*}\right) & f_{3}\left(\bar{X}_{2}^{*}\right) \\
f_{1}\left(\bar{X}_{3}^{*}\right) & f_{2}\left(\bar{X}_{3}^{*}\right) & f_{3}^{*}\left(\bar{X}_{3}^{*}\right)
\end{array}\right]
$$

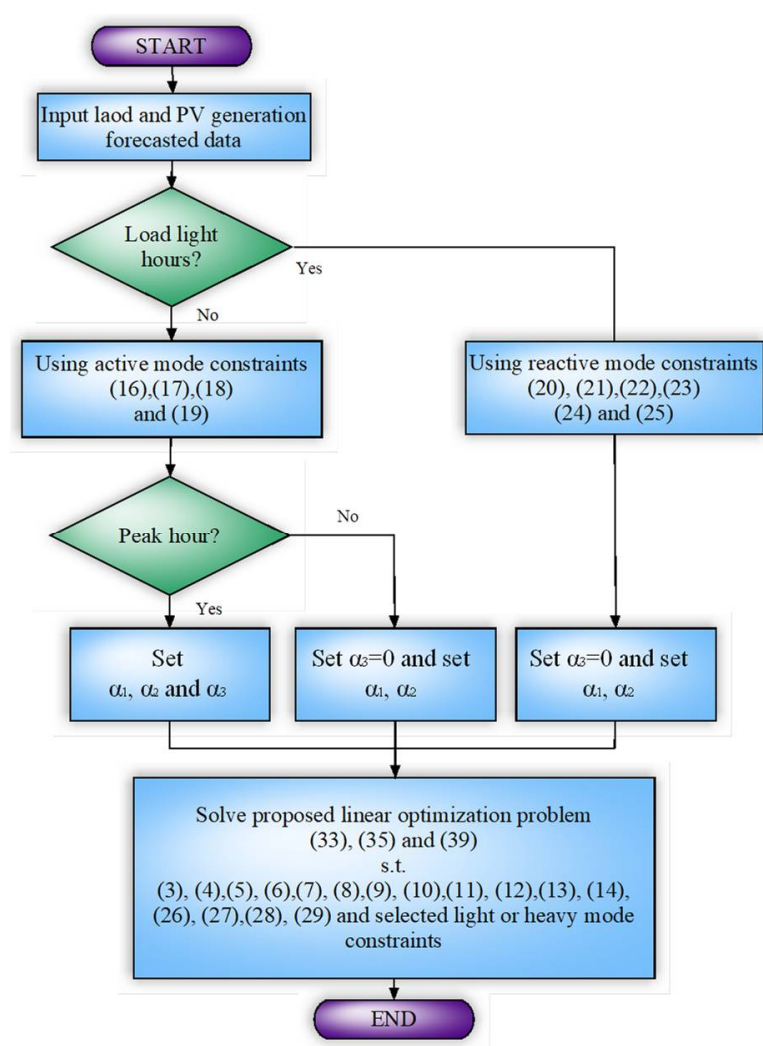

Fig. 7. Flow-chart of the proposed multi-objective optimization and decision-making model based on the epsilon-constraint method.

In the payoff table, $f_{i}^{*}\left(\bar{X}_{i}^{*}\right)$ (rows) is the optimal value of objective function $f_{i}$ in the presence of main constraints and the values of $f_{j}^{*}\left(\bar{X}_{i}^{*}\right)$ (columns) at $\bar{X}_{i}^{*}$, which represents the optimal solution for $f_{i}$. Therefore, the minimum and maximum of each $i^{\text {th }}$ row is considered as $f_{i_{\min }}$ and $f_{i_{\text {max }}}$. Details of the pay-off table and its calculation are found in [29]. As previously mentioned, selection of the best solution is the preference of the decision maker. In the proposed method, the output results of the multi-objective optimization (i.e., the Pareto set members) must first be set to the same scale as shown in Equation (44)-(47).

$$
\begin{gathered}
\text { Pareto set }=\left[\begin{array}{cccc}
f_{11} & f_{12} & \cdots & f_{1 p} \\
\vdots & \vdots & & \vdots \\
f_{q 1} & f_{q 2} & \cdots & f_{q p}
\end{array}\right] \\
f_{1}^{\prime}(i)=\text { Pareto set }(i, 1) \quad i=1,2, \ldots, q
\end{gathered}
$$

$$
\begin{gathered}
f_{2}^{\prime}(i)=\text { Paretoset }(i, 2) \times\left(\frac{d_{1}}{d_{2}}\right) \quad i=1,2, \ldots, q \\
\vdots \\
f_{p}^{\prime}(i)=\text { Paretoset }(i, p) \times\left(\frac{d_{1}}{d_{p}}\right) \quad i=1,2, \ldots, q
\end{gathered}
$$

Where $d_{i}$ is the difference between the values of $f_{i_{\text {max }}}$ and $f_{i_{\text {min }}}$. Afterwards, these functions are weighted as can be seen in (48) based on their importance with $\alpha_{1}, \alpha_{2}, \ldots, \alpha_{p}$ coefficients which are bound by Equation (49). Pareto set is composed from multitude non-dominate points and the most preferred point can be chosen by minimizing (48).

$$
\begin{gathered}
g(s)=\alpha_{1} f_{1}^{\prime}(s)+\alpha_{2} f_{2}^{\prime}(s)+\cdots+\alpha_{p} f_{p}{ }^{\prime}(s) \\
\sum_{k} \alpha_{k}=1
\end{gathered}
$$

$s^{*}$ indicates the iteration number at which the optimal value for $g\left(s^{*}\right)$ was encountered.

In this way, the most preferred solution is found with respect to the importance of objective functions set by the priority coefficients $\alpha_{k}$.In this work, $\alpha_{1}, \alpha_{2}$, and $\alpha_{3}$ ccorrespond to voltage profile, power losses, and peak load power functions, respectively.

\section{Numerical Results}

To validate it and evaluate its performance, the proposed multi-objective and decision-making approach was tested on the Standard IEEE 33-bus network which is shown in Fig. 8. The reference voltage and power at all buses is 12.66 $\mathrm{kV}$ and 1 MVA, respectively. More detailed information about this standard test network can be obtained in [30].

At bus 30, a 5 MW battery unit and a 1.054 MW PV generation unit are jointly connected. This joint connection of the battery and PV units corresponds to the DG structure previously presented in Figure 1. The solar radiation profile shown in Fig. 9 has been considered for the MPPT algorithm. An oversizing of inverters capacities was done to support the network reactive power in the presence of a DG unit of this size. Accordingly, an inverter capacity of 1.112 MW was set.

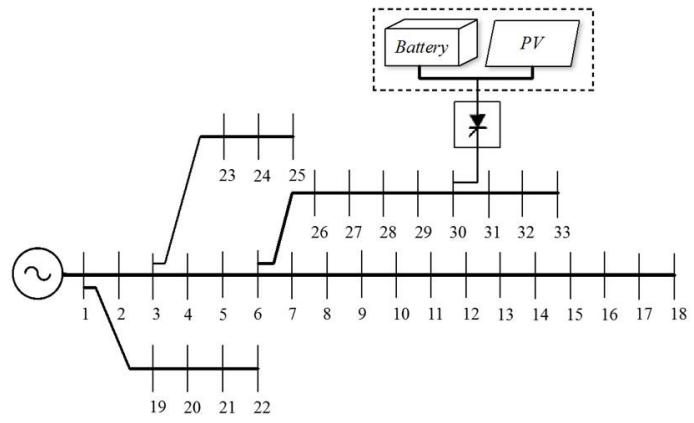

Fig. 8. Standard IEEE 33-bus test network

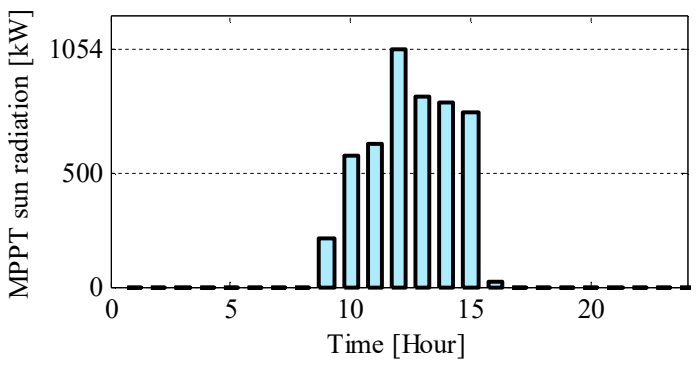

Fig. 9. Solar radiation profile used for MPPT. 
The operational planning of network for a 24-hour time period was determined based on the optimal solutions associated with the different objective functions. It must be noted that the nonlinear equations for peak hour are solved by CONOPT solver within 2.644 seconds. This runtime has been reduced to 0.281 seconds by the proposed model with linearized equations.

It is necessary to prove the linear independence of the objective functions. The payoff table must be evaluated in order to do this:

$$
\Phi=\left[\begin{array}{lll}
f_{1}^{*}\left(\bar{X}_{1}^{*}\right) & f_{2}\left(\bar{X}_{1}^{*}\right) & f_{3}\left(\bar{X}_{1}^{*}\right) \\
f_{1}\left(\bar{X}_{2}^{*}\right) & f_{2}^{*}\left(\bar{X}_{2}^{*}\right) & f_{3}\left(\bar{X}_{2}^{*}\right) \\
f_{1}\left(\bar{X}_{3}^{*}\right) & f_{2}\left(\bar{X}_{3}^{*}\right) & f_{3}^{*}\left(\bar{X}_{3}^{*}\right)
\end{array}\right]=\left[\begin{array}{ccc}
8.975 & 3.745 & 1.378 \\
13.459 & 3.653 & 1.548 \\
24.234 & 3.654 & 1.258
\end{array}\right]
$$

As can be seen in Equation (50), when $f_{l}$ is minimum, $f_{2}$ is maximum and any attempt to reduce peak power causes an increase in the voltage profile's objective function. Similar behavior can be seen between $f_{l}$ and $f_{3}$. In addition, according to the payoff table it is clear that the minimum point of peak power corresponds to the highest point of power losses. This is sufficient to prove that the three functions are linearly independent.

Voltage deviation (from the base value) is shown in comparison with the peak power in Fig. 10 (a). It can be seen that voltage deviation tends to increase as peak reduction is favored, the voltage deviation increases. In Fig. 10 (b), a similar behavior is seen for voltage profile improvement vs power loss.
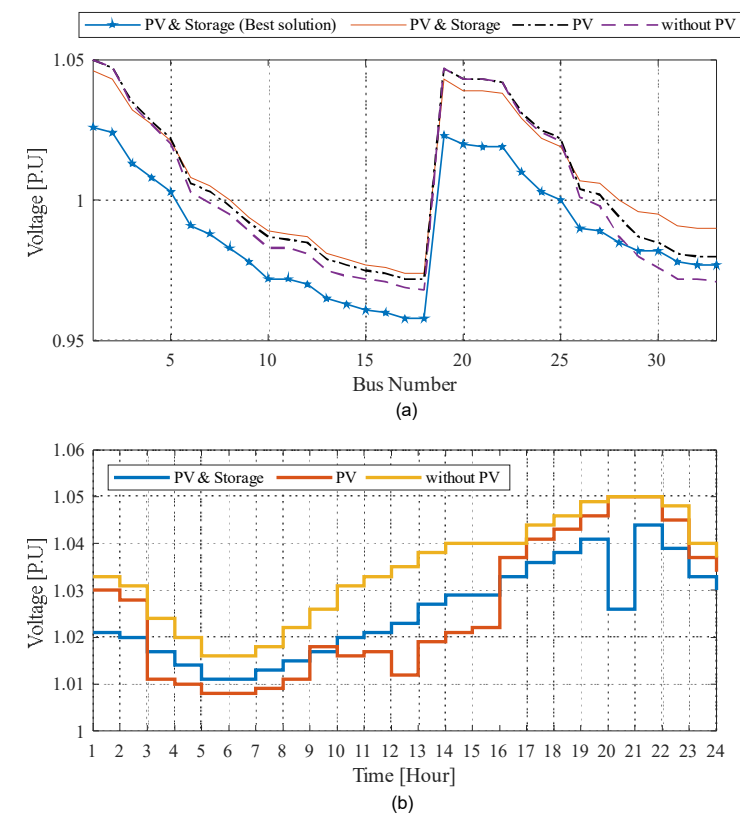

Fig. 11. Voltage profile of (a) the system at the peak hour, (b). the slack bus for all hours.

When grid controllers are used to decrease the losses, they cause an increase in voltage deviation. Given that this is a multi-objective optimization method, all three functions need to be considered simultaneously. In Fig. 10(c), the collective optimal solutions which reduce all three functions are shown.

Fig. 11(a), shows the peak-hour voltage profile for the different modes of operation. Without DG, the tap-changer of the main substation acts solely for voltage control, setting the voltage at the maximum permissible value to prevent a voltage drop. Installation of PV generation results in an improved voltage profile during its generation hours. In addition, during peak load hours, the voltage profile is close to 1 p.u. as a result of reactive power control. The joint connection of storage and PV results in a further improved voltage profile. This is caused by active power injection to the grid being added as a decision variable in the modeling of the problem.

The optimal solution from the proposed multi-objective optimization model (minimizing voltage deviation, peak load power, and power losses simultaneously) is plotted in the same figure for comparison. It can be seen that order to reduce peak power, the tap-changer acts by decreases the voltage level.

For the entire 24-hour operational decision-making horizon, the hourly variation of voltage at the main station is shown in Fig. 11(b). It can be seen that the tap changer is clearly subject to less pressure when the DG unit is connected. The voltage profile is further improved when the storage unit is present, with the operation of the tap changer decreased and is not operated in the non-preferred zones i.e., close to its upper and lower limits. The recorded losses at peak-hour losses under different conditions are listed in Table 3. It can be seen that without using the optimization model, the use of PV generation actually increases grid losses. However, connecting the storage unit converts the DG unit to a dispatchable source thereby reducing the losses. Employing the proposed multi-objective optimization and decision-making framework results in a decrease of losses and peak power for both cases, in addition to achieving an appropriate voltage. Moreover, the peak load was reduced from 3.715 to $3.682 \mathrm{MW}$ as a result of the enhanced voltage profile since power is dependent on voltage.

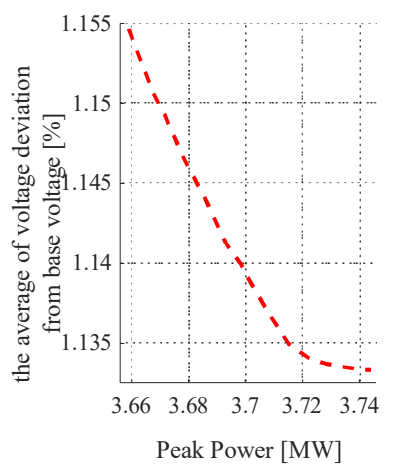

(a)

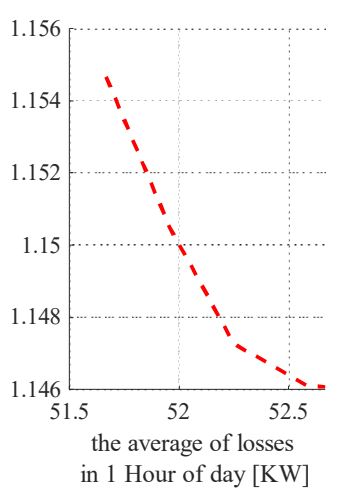

(b)

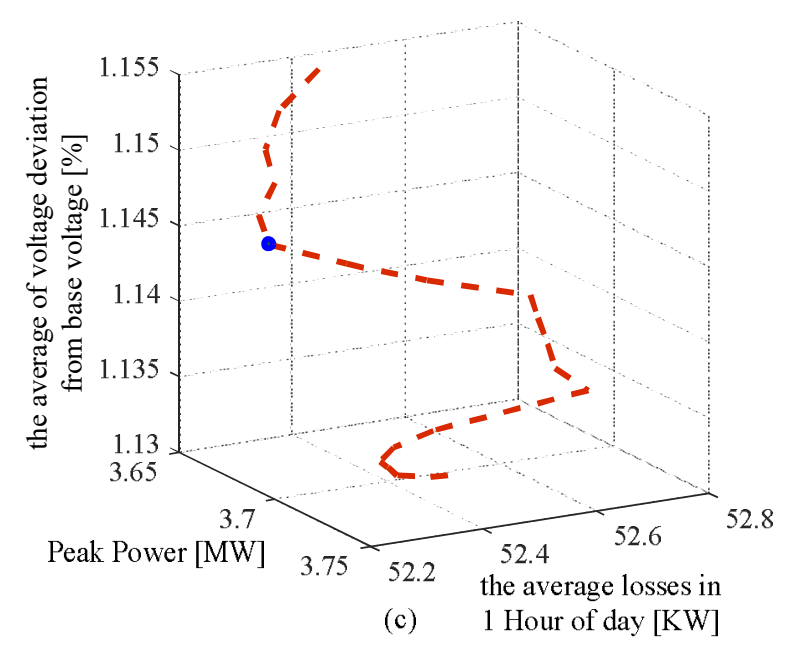

Fig. 10. Multi-objective reference points: (a). Voltage deviation vs. peak power, (b). voltage deviation vs. average losses, and (c). voltage deviation vs. peak power vs. average losses. 
Table 3 Grid losses.

\begin{tabular}{|c|c|c|c|c|}
\hline & $\begin{array}{c}\text { Without } \\
\text { DG }\end{array}$ & DG & $\begin{array}{c}\text { DG \& } \\
\text { Storage }\end{array}$ & $\begin{array}{c}\text { Best } \\
\text { Solution }\end{array}$ \\
\hline $\begin{array}{c}\text { Losses at peak load } \\
{[\mathrm{kW}]}\end{array}$ & 146 & 155 & 118 & 106 \\
\hline
\end{tabular}

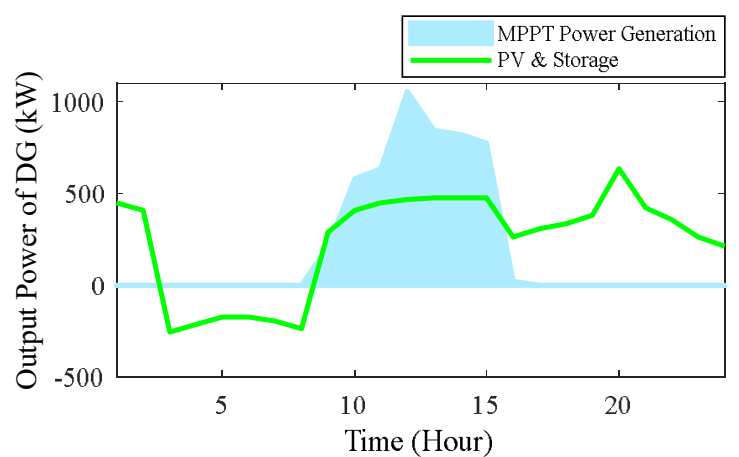

Fig. 12. DG-grid power exchange.

The use of storage to shift the injection from hours of peak production to those of peak consumption is another way to reduce peak power. This is shown in Fig. 12.

An alternative method to reinforce network stability is absorption of power by storage during low-load hours. The green diagram in Fig. 13 shows that storage absorbs 1259 $\mathrm{kWh}$ during those hours.

In fact, the battery is connected to the network as a load, which prevents low loading of network by charging the battery during off-peak hours. This amount of power is available to be injected into the network in necessary situations.

Those absorption and injection operations ensure that the battery is not harmed, as the SoC of battery constrained within appropriate limitations. Fig. 14 shows the battery SoC throughout the day, confirming that it stays within the range of $15-85 \%$.

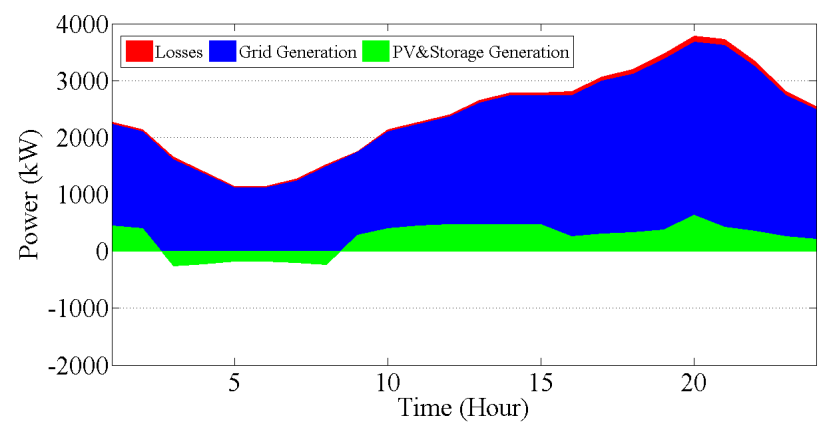

Fig. 13. Injected active power to the grid.

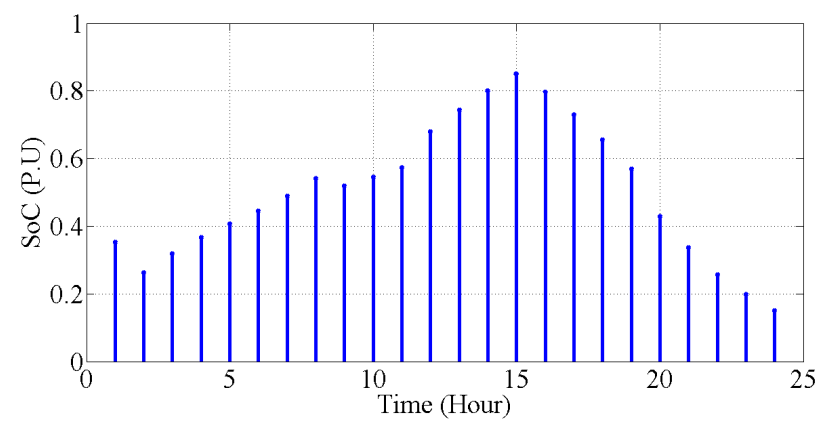

Fig. 14. The hourly SoC of the battery.

\section{Conclusion}

In this study, a voltage control strategy is proposed in which the operation of different grid elements in active distribution networks is coordinated, resulting in a multiobjective optimization framework. This conformity in operation results in reduced stress and increased lifetime of equipment. To achieve this, linear multi-objective optimization was proposed which simultaneously minimizes the network voltage profile (deviation from reference voltage), peak load power, and power losses as objective functions. Linearizing the inverter capability curve was performed by dividing grid operation to heavy and light modes and linearizing around specified operating power for each case. Linearized equations for constraints and load flow were used to enhance the computational performance of the model. Moreover, a decision-making process has been proposed to find the Pareto optimality and select the best schedule. The case study confirmed proper selection of a daily schedule, in which the battery SoC was kept within allowable limits. Tap changers were prevented from operation in non-preferred zones and PVs were well employed, thereby successfully simultaneously obtaining a suitable voltage profile, reduced peak load power, and reduced power losses.

\section{Appendix}

Linearization of the capability curve linearizing is carried out by classifying its operation into two modes: heavy and light operation, as demonstrated in Fig. 3.

In the first, during hours of high consumption, the DG unit (comprised of the PV and battery storage units) first attends to the active power supply before activating its ability for reactive power control ability. Fig. 3(a) demonstrates the operating range during the heavy load mode which shows the linearization of the inverter capability curve with lines $l_{1}$ and $l_{2}$. The limitations of reactive power are shown using lines $l_{3}$ and $l_{4}$.

For the second light load mode the DG unit operates as an ancillary service provider. In this case the injection of active power is less emphasized. Therefore, as shown in Fig. 3(b), the active power exchanged is limited to a more confined range. The operating boundaries in this mode are visualized using lines $l_{5}$ to $l_{10}$ in Fig. 3(b).

$$
\begin{aligned}
& l_{1}=P-\left(\frac{S_{i n v}-P\left(Q_{\max }\right)}{-Q_{\max }}\right) \times Q-S_{i n v} \\
& l_{2}=P-\left(\frac{S_{i n v}-P\left(-Q_{\max }\right)}{Q_{\max }}\right) \times Q-S_{i n v} \\
& l_{3}=Q+Q_{\max } \quad l_{4}=Q-Q_{\max }
\end{aligned}
$$

$$
\begin{aligned}
& l_{5}=P-\left(\frac{P_{\max }}{S_{i n v}-\sqrt{S_{i n v}{ }^{2}-P_{\max }^{2}}}\right) \times Q-\left(\frac{P_{\max }}{S_{i n v}-\sqrt{S_{i n v}{ }^{2}-P_{\max }^{2}}}\right) \times S_{i n} \\
& l_{6}=P+\left(\frac{P_{\max }}{S_{i n v}-\sqrt{S_{i n v}{ }^{2}-P_{\max }^{2}}}\right) \times Q+\left(\frac{P_{\max }}{S_{i n v}-\sqrt{S_{i n v}{ }^{2}-P_{\max }^{2}}}\right) \times S_{i \hbar} \\
& l_{7}=P+\left(\frac{P_{\max }}{S_{i n v}-\sqrt{S_{i n v}{ }^{2}-P_{\max }^{2}}}\right) \times Q-\left(\frac{P_{\max }}{S_{i n v}-\sqrt{S_{i n v}{ }^{2}-P_{\max }^{2}}}\right) \times S_{i \kappa} \\
& l_{8}=P-\left(\frac{P_{\max }}{S_{i n v}-\sqrt{S_{i n v}{ }^{2}-P_{\max }{ }^{2}}}\right) \times Q+\left(\frac{P_{\max }}{l_{i n v}-\sqrt{S_{i n v}{ }^{2}-P_{\max }^{2}}}\right) \times S_{i n} \\
& l_{9}=P-P_{\max }
\end{aligned}
$$




\section{References}

[1] IRENA (2017), REthinking Energy 2017: Accelerating the global energy transformation. International Renewable Energy Agency, Abu Dhabi.

[2] IFC (2017), Energy Storage Trends and Opportunities in Emerging Markets. International Finance Corporation.

[3] Y. P. Agalgaonkar, B. C. Pal, R. A. Jabr; "Distribution Voltage Control Considering the Impact of PV Generating of Tap Changers and Autonomous Regulators", IEEE. Trans. Power Syst, vol. 29, no. 1, pp. $182-192,2014$

[4] Z. Ziadi, M. Oshiro, T. Senjyu, A. Yona, N. Urasaki, T. Funabashi, C. H. Kim; "Optimal Voltage Control Using Inverters Interfaced With PV Systems Considering Forecast Error in a Distribution System", IEEE. Trans. Sustain. Energy, vol. 5, no. 2, pp. $682-690$, 2014.

[5] N. Hashemipour, T. Niknam, J. Aghaei, H. Farahmand, M. Korpås, M. Shafie-khah, J. P. S. Catalao, "A linear multi-objective operation model for smart distribution systems coordinating tap-changers, photovoltaics and battery energy storage," in Proc. 2018 Power Systems Computation Conference (PSCC), Dublin, Ireland, 11-15 June 2018.

[6] D. H. Spatti, I. N. da Silva, W. F. Usida, R. A. Flauzino; "Real-Time Voltage Regulation in Power Distribution System Using Fuzzy Control", IEEE Trans. Power. Del, vol. 25, no. 2, pp. 1112 - 1123 2010 .

[7] H. G. Yeh, D. F. Gayme, S. H. Low; "Adaptive VAR Control for Distribution Circuits with Photovoltaic Generators", IEEE Trans. Power. Syst, vol. 27, no. 3, pp. 1656 - 1663, 2012.

[8] H. E. Z. Farag, E. F. El-Saadany; “A Novel Cooperative Protocol for Distributed Voltage Control in Active Distribution Systems", IEEE. Trans. Power. Syst, vol. 28, no. 2, pp. 1645 - 1656, 2013.

[9] M. N. Kabir, Y. Mishra, G. Ledwich, Z. Y. Dong, K. P. Wong; "Coordinated Control of Grid Connected Photovoltaic reactive power and battery Energy Storage Systems to Improve to the Voltage Profile of a Residential Distribution Feeder", IEEE. Trans. Ind. Info, Vol. 10, no. 2, pp. $967-977,2014$.

[10] V. Calderaro, G. Conio, V. Galdi, G. Massa, A. Piccolo; "Optimal Decentralized Voltage Control for Distribution Systems with Inverter-Based Distributed Generators", IEEE. Trans. Power. Syst, vol. 29 , no. 1 , pp. $230-241,2014$.

[11] I. Džafić, R. A. Jabr, E. Halilovic, B. C. Pal; “A Sensitivity Approach to Model Local Voltage Controllers in Distribution Networks", IEEE. Trans. Power Syst, vol. 29, no. 3, pp. 1419 - 1428, 2014.

[12] K. M. Muttaqi, A. D. T Le, M. Negnevitsky, G. Ledwich; "A Coordinated Voltage Control Approach for Coordination of OLTC, Voltage Regulator, and DG to Regulator Voltage in a Distribution Feeder", IEEE. Trans. Ind. Appl, vol. 51, no. 2, pp. 1239 - 1248, 2015.

[13] D. Ranamuka, A. P. Agalgaonkar, K. M. Muttaqi; “Online Voltage Control in Distribution Systems with Multiple Voltage Regulating Devices", IEEE. Trans. Sustain. Energy, vol. 5, no. 2, pp. 617 - 628, 2014.

[14] Sh. N. Salih, P. Chen; "On Coordinated Control of OLTC and Reactive Power Compensation for Voltage Regulation in Distribution Systems with Wind Power", IEEE. Trans. Power. Syst, vol. 31, no. 5, pp. $4026-4035,2016$
[15] J. V. Appen, T. Stetz, M. Braun, A. Schmiegel; "Local Voltage Control Strategies for PV Storage Systems in Distribution Grids", IEEE. Trans. Smart. Grid, vol. 5, no. 2, pp. 1002 - 1009, 2014.

[16] Y. Wang, K. T. Tan, X. Y. Peng, P. L. So; "Coordinated Control of Distributed Energy Storage Systems for Voltage Regulation in Distribution Network", IEEE. Trans. Power. Del, vol. 31, no. 3, pp. $1132-1141,2016$

[17] Sh. A. Abdelrazek, S. Kamalasadan; "A Weather Based Optimal Storage Management Algorithm for PV Capacity Firming", IEEE. Trans. Ind. Appl, vol. 52, no. 6, pp. 5175 - 5184, 2016.

[18] J. D. Watson, N. R. Watson, B. Das; "Effectiveness of power electronic voltage regulators in the distribution network", IET Gener. Transm. Distrib. vol. 10, no. 15, pp. 3816-3823, 2016.

[19] D. Ranamuka, A. P. Agalgaonkar, K. M. Muttaqi; "Online Coordinated Voltage Control in Distribution Systems Subjected to Structural Changes and DG Availability”, IEEE. Trans. Smart. Grid, vol. 7, no. 2, pp. $580-591,2016$.

[20] D. Ranamuka, A. P. Agalgaonkar, K. M. Muttaqi; "Examining the Interactions between DG Units and Voltage Regulating Devices for Effective Voltage Control in Distribution Systems", IEEE. Trans. Ind. Appl, vol. 53, no. 2, 2017.

[21] P. Jahangiri, D. C. Aliprantis; "Distributed Volt/VAr Control by PV Inverters", IEEE. Trans. Power. Syst, vol. 28, no. 3, pp. 3429-3439, 2013.

[22] A. M. García, R. A. Mastromauro, T. García-Sánchez, S. Pugliese, M. Liserre, S. Stasi; "Reactive Power Flow Control for PV Inverters Voltage Support in LV Distribution Networks", IEEE. Trans. Smart. Grid, vol. 8, no. 1, pp. 447 - 456, 2017.

[23] M. E. Baran, I. M. El-Markabi; “A Multiagent-Based Dispatching Scheme for Distributed Generators for Voltage Support on Distribution Feeders", IEEE. Trans. Power. Syst, vol. 22, no. 1, pp. 52-89, 2007

[24] F. A. Viawan, D. Karlsson; "Combined Local and Remote Voltage and Reactive Power Control in the Presence of Induction Machine Distributed Generation", IEEE. Trans. Power Syst, vol. 22, no. 4, pp. 2003-2012, 2007.

[25] N. Daratha, B. Das, J. Sharma; "Coordination between OLTC and SVC for Voltage Regulation in Unbalanced Distribution System Distributed Generation”, IEEE. Trans. Power. Syst, vol. 29, no. 1, pp. $289-299,2014$

[26] Hadi Saadat, "Power System Analysis", McGraw Hill, USA. Third Edition. 2002.

[27] A. Garces; "A Linear Three-Phase Load Flow for Power Distribution Systems”, IEEE. Trans. Power. Syst, vol. 31, no. 1, pp. $827-828$, 2016

[28] T. A. Short; "Electric power distribution handbook", ISBN 0-84931791-6, CRC Press, 2004, section 5.3.4.

[29] J. Aghaei, N. Amjady, H.A. Shayanfar; "Multi-objective electricity market clearing considering dynamic security by lexicographic optimization and augmented epsilon constraint method", Elsevier, Applied Soft Computing, vol. 11, no. 4, pp. 3846-3858, 2011.

[30] M. A. Kashem, V. Ganapathy, G.B. Jasmon, M.I. Buhari; "A novel method for loss minimization in distribution networks", In Electric Utility Deregulation and Power Technologies, 2000. in Proc. DRPT International Conference, 2000. 